\title{
Insertion of fully covered self-expandable metal stent during balloon-assisted ERCP in patient with surgically altered upper gastrointestinal anatomy
}

The presence of complex, surgically altered gastrointestinal (GI) anatomy poses a diagnostic and therapeutic challenge to the endoscopist treating patients with pancreaticobiliary disorders. Placing fully covered metal stents into the bile duct during endoscopic retrograde cholangiopancreatography (ERCP) through standard forward-viewing scopes, such as double- and single-balloon enteroscopes and colonoscopes, is impossible as the working channel is too small, even with the new-generation short double-balloon enteroscopes [1, 2]. Herein, we present a novel technique to insert fully covered metal stents into the bile duct using balloon-assisted ERCP, whereby the overtube is used as a giant working channel.

A 43-year male patient who had undergone Whipple operation with Roux-en-Y hepaticojejunostomy for a "pancreatic cyst" (or choledochal cyst) at age 3 years presented with choledocholithiasis and cholangitis. The magnetic resonance cholangiopancreatography showed a tight hepaticojejunostomy stricture and dilated bile ducts full of stones. ERCP failed at two different medical centers using traditional methods.

We performed a double-balloon enteroscopy-assisted ERCP ( $\triangleright$ Video 1 ). The hepaticojejunostomy was very narrow. A long $(650 \mathrm{~cm})$ guidewire (Metro; Cook Medical, Bloomington, Indiana, USA) was advanced through the narrow opening of the hepatico-jejunal anastomosis. A catheter was advanced over the long wire. Cholangiography revealed a tight and short anastomotic stricture (ฉ Fig.1, - Video 1). The hepaticojejunostomy was dilated with a $6 \mathrm{~mm}$ through-thescope balloon (Hercules; Cook Medical) ( $\triangleright$ Fig. 1, $\triangleright$ Video 1). The guidewire was inserted deep into into the bile duct system and the enteroscope was withdrawn, leaving the overtube in place as a working channel. As the fully covered self-expandable metal stent (fcSEMS) delivery system
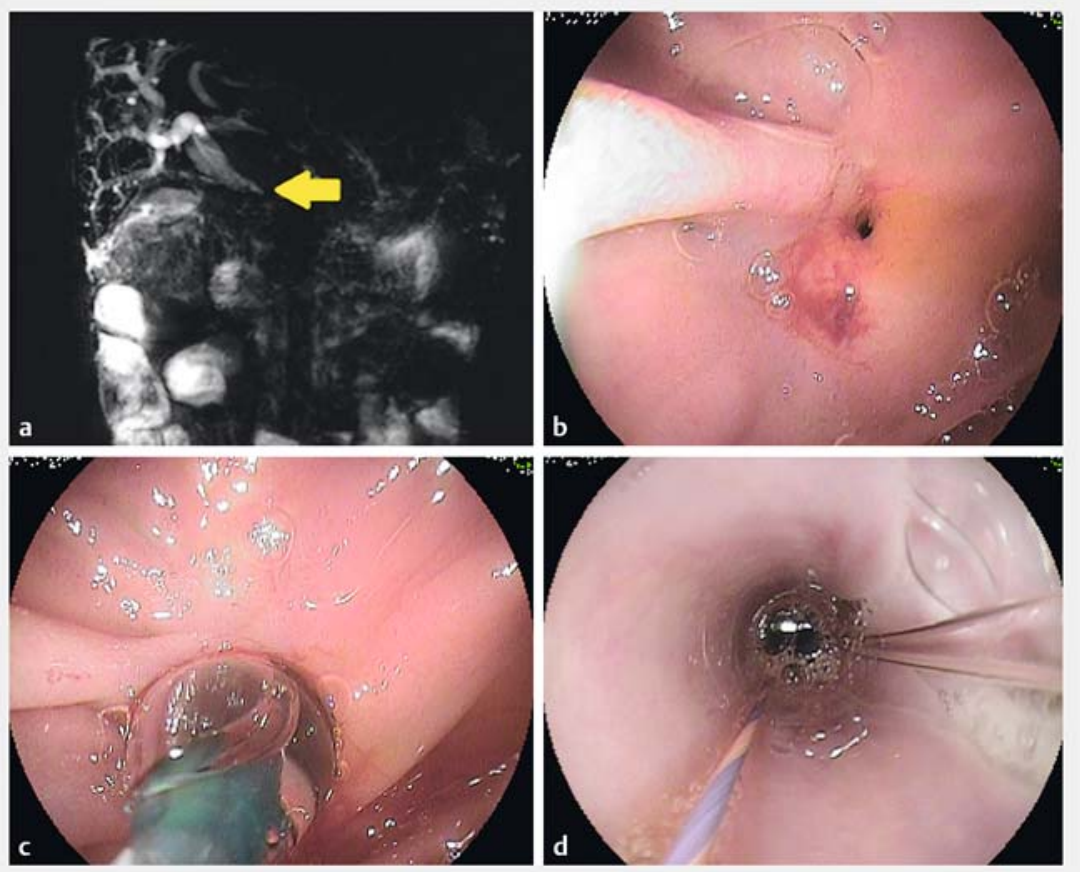

- Fig. 1 Balloon-assisted endoscopic retrograde cholangiopancreatography. a Magnetic resonance cholangiopancreatography revealed a tight distal bile duct stricture (yellow arrow). b Tight opening of the hepaticojejunostomy. c Balloon dilation of the hepaticojejunostomy. d The balloon-assisted enteroscopy overtube worked as a giant working channel. The wire was left inside, connecting the bile ducts to the operator. The operator then advanced a fully covered metal stent, over-the-wire and through-the-overtube, using radiological guidance, and then successfully inserted the stent inside the bile duct.

is shorter than the length of the overtube, the overtube was incised on the side just before the mouthpiece, and the delivery system was inserted under fluoroscopic guidance ( $\triangleright$ Video 1 ). The wire was tightly grasped with a hemostat forceps. An fcSEMS $10 \times 40 \mathrm{~mm}$ (Evolution biliary SEMS; Cook Medical) was deployed, resulting in excellent bile duct drainage. A gastroscope was then inserted through the overtube to inspect the fully deployed stent and to remove stones during direct cholangioscopy. Multiple stones were extracted. Because there were several large stones inside the massively dilated bile duct, small plastic stents were insert- ed through the fcSEMS to guarantee bile flow. Cholangitis and cholestasis resolved, and the patient was discharged home 2 days later.

To the best of our knowledge, this is the first video report on successful insertion of fully covered metal stents during balloon-assisted ERCP. Our case also highlights a case of "extreme endoscopy," where multiple endoscopes, accessories, and instruments are used to solve a complex pancreaticobiliary problem. Not only did balloon-assisted ERCP reach the bile ducts, but the balloon-assisted enteroscopy overtube worked as a giant working channel, allowing the operator to ad- 


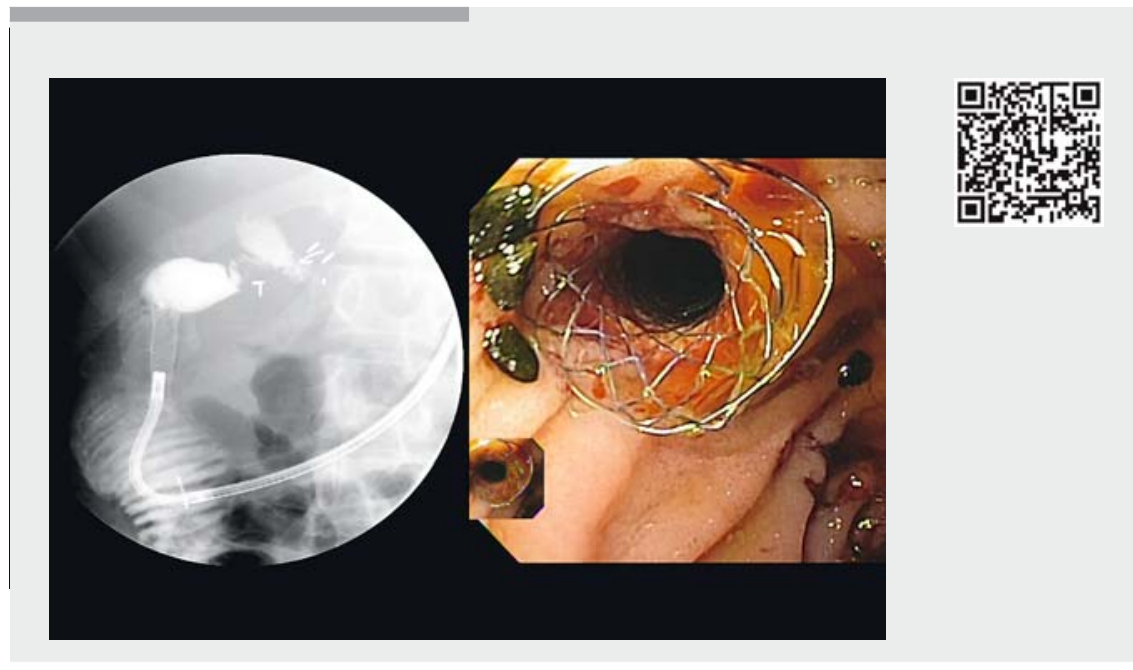

Video 1 The key steps of balloon-assisted endoscopic retrograde cholangiopancreatography. Of particular interest is the use of the overtube as a giant "access" channel to the bile ducts. The overtube, which remained in situ after the enteroscope had reached the biliary limb, served two main purposes: 1) access toward the bile ducts, permitting the insertion of additional scopes to perform direct cholangioscopy; and 2) working channel, which allowed therapeutic interventions to be performed, and the novel concept of inserting a large-diameter metal stent through the overtube, which indeed became a "giant" working channel.

vance a fully covered metal stent overthe-wire and through-the-overtube, using radiological guidance, and to successfully insert the stent inside the bile duct.

Endoscopy_UCTN_Code_TTT_1AR_2AZ

\section{Competing interests}

Klaus Mönkemüller is a speaker and consultant for Ovesco Germany and Cook Medical USA.

\section{Acknowledgment}

Dr. Ivan Jovanovic performed this work during his Fulbright Scholarship at the University of Alabama at Birmingham. Dr. Klaus Mönkemüller received the ASGE Research Award 2014: Development of an ex vivo ERCP Model.

\section{References}

[1] Skinner M, Velázquez-Aviña J, Mönkemüller K. Using balloon-overtube-assisted enteroscopy for postoperative endoscopic retrograde cholangiopancreatography. Therap Adv Gastroenterol 2014; 7: 269 - 279

[2] Skinner M, Popa D, Neumann H et al. ERCP with the overtube-assisted enteroscopy technique: a systematic review. Endoscopy 2014; 46: $560-572$

\section{Bibliography}

Dol https://doi.org/10.1055/s-0043-119686

Published online: 3.11.2017

Endoscopy 2018; 50: E20-E21

(C) Georg Thieme Verlag KG

Stuttgart · New York

ISSN 0013-726X

Benjamin A. Hewitt ${ }^{1}$, Ivan Jovanovic ${ }^{1}$, Alvaro Martínez-Alcalá ${ }^{1}$, P. Thomas Kröner ${ }^{1}$, Marco

D’Assunçao ${ }^{1}$, Klaus Mönkemüller ${ }^{1,2}$

1 Basil Hirschowitz Endoscopic Center of Excellence, Division of Gastroenterology and Hepatology, University of Alabama at Birmingham, Birmingham, United States

2 Department of Gastroenterology, Frankenwald Klinikum, Kronach, Germany

\section{Corresponding author}

\section{Klaus Mönkemüller, MD, PhD}

Division of Gastroenterology, Helios

Frankenwald Klinik, Friesenerstr. 44 ,

Kronach, Germany

Fax: +49-9261-597918

moenkemueller@yahoo.com

\section{ENDOSCOPY E-VIDEOS}

https:|/eref.thieme.de/e-videos

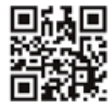

Endoscopy E-Videos is a free access online section, reporting on interesting cases and new

techniques in gastroenterological endoscopy. All papers include a high quality video and all contributions are freely accessible online.

This section has its own submission website at

https://mc.manuscriptcentral.com/e-videos 